\title{
The Role of Price Floor in a Differentiated Product Retail Market $^{1}$
}

\author{
Barna Bakó ${ }^{2}$ \\ Corvinus University of Budapest \\ Hungary
}

${ }^{1}$ I would like to thank the anonymous referee for the valuable comments and suggestions, which led to substantial improvements in the paper. I gratefully acknowledge financial support from the Hungarian Competition Authority.

2e-mail: barna.bako@uni-corvinus.hu 


\begin{abstract}
The ability of a manufacturer to enhance competition among its retailers by imposing a price floor was recently introduced in the literature. The purpose of this article is to revisit this anti-collusive explanation of the retail price maintenance in a more general model in which we introduce asymmetric retailers. We find that a manufacturer can amplify the retail market's competition by imposing a price floor when retailers sell differentiated products. This result contradicts the prevailing concept of retail price maintenance.
\end{abstract}

Keywords Retail price maintenance, Price floor, Collusion

JEL Classification: C61, D43, L41, K21 


\section{Introduction}

Price restrictions are undoubtedly among those practices that are more severely treated by antitrust authorities than any other vertical restraint, however there is a trend towards a more flexible attitude. ${ }^{1}$ Yet, retail price maintenance (RPM) and price floors are often considered per se illegal. ${ }^{2,3}$

In a recent article, Overvest (2010) has argued that a monopolist manufacturer may in fact be able to increase its profit imposing price floor because this makes a downstream market collusion less profitable. In essence, if retailers interact in an infinite number of times they may form a cartel which causes the traditional double marginalization problem to the manufacturer. By imposing a price floor the producer may destabilize the cartel which increases its profit. The argument is potentially an important one because it supports the available empirical evidences which has contradicted the pro-collusion theory of the price maintenance. However, the result is crucially based on a special model, the infinitely repeated Bertrand game with homogeneous good, in which the core problem of double marginalization does not arise when retailers can not collude. This is not the case when we introduce differentiated products. Everyday observations suggest that firms expend considerable efforts to differentiate the products they sell from the products of their competitors. As a result, we should consider the incentive for price floor and the impact of it in an industry in which retailers add extra value to the product they sell. In this article we reconsider the Overvest (2010) model and the downstream

\footnotetext{
${ }^{1}$ The US Supreme Court recently revisited the per se ban of the price fixing and replaced a nearly 100 year old precedent by adopting a rule of reason standard for analyzing resale price maintenance, see Leegin Creative Leather Products, Inc. v. PSKS, Inc, 551 U.S. 877,127 S. Ct. 2705 (2007)

${ }^{2}$ Throughout this analysis the minimum resale price and the price floor terms are used synonymously.

${ }^{3}$ For a broad overview of the effects of the RPM, see Overstreet (1983).
} 
market is described by a Bertrand duopoly model with differentiated products. We show that a profit maximizing manufacturer selling its product through differentiated Bertrand firms has the incentive to impose a price floor on its product to destabilize a potential tacit collusion and increase competition among retailers. The intuition behind this result is that retailers find the deviation from a cartel agreement more profitable or less costly in the presence of a price floor than without it, and so, a cartel which would be stable in the absence of a price maintenance can be unstable when manufacturer introduces a price floor. Thus, a retail price maintenance can boost competition among retailers which increases the manufacturer's profit. Furthermore, we prove that a price floor being introduced to unstabilize a retailer cartel is a decreasing function of the product differentiation.

\section{The Model}

We assume the following set-up. A monopolist manufacturer sells its product to final consumers through two asymmetric retailers. The marginal costs of production are $c$. The retailers have no additional costs in obtaining the products from the manufacturer.

Demands are given by

$$
D_{i}\left(p_{i}, p_{j}\right)=\alpha-p_{i}+\beta p_{j}
$$

where $\{i, j\}=\{A, B\}$ with $\alpha>0$ and $\beta \in(0,1)$. We interpret parameter $\beta$ as the degree of product differentiation between final products, for $\beta$ close to 1 retailers sell close substitutes, while for $\beta$ close to 0 they supply to almost independent markets.

The timing of the game is as follows. First, the manufacturer sets its wholesale price $p_{w}$ and possibly a price floor $p_{f} \cdot{ }^{4}$ Second, retailers observe the wholesale

\footnotetext{
${ }^{4}$ Note, that here we assume linear prices, a contract specifying a payment $T_{i}\left(q_{i}\right)=p_{w} q_{i}$ from retailer $i$ to manufacturer.
} 
price and compete in Bertrand-fashion or they are engaged in tacit collusion in the market stage where the retailers interact repeatedly many times without knowing the exact timing of the ending stage of the game.

Here some remarks need to be made. Firstly, we suppose that the retailers are not aware of the ending of the game, however they know the probability of the stage game which is going to be the last one and this probability $(1-\rho)$ does not vary during the time. Furthermore, we suppose that firms use a common discount factor of $\delta \in(0,1)$ and each retailer can observe and remember the history of the game. These information constitute common knowledge to the firms. Firms maximize their discounted pay-offs.

We solve the model using backward induction. The retailers' one stage profit maximization problem can be given by

$$
\max _{p_{i}} \pi_{i}=\left(p_{i}-p_{w}\right) D_{i}\left(p_{i}, p_{j}^{*}\right) \quad i, j=A, B \quad i \neq j .
$$

This yields the equilibrium prices and profits of the stage game

$$
\begin{gathered}
p_{i}^{*}=\frac{\alpha+p_{w}}{2-\beta} \quad i=A, B . \\
\pi_{i}^{*}=\frac{\left[\alpha-(1-\beta) p_{w}\right]^{2}}{(2-\beta)^{2}} \quad i=A, B .
\end{gathered}
$$

Thus, the manufacturer's problem can be given by

$$
\max _{p_{w}} \pi_{m}=\left(p_{w}-c\right)\left[D_{i}\left(p_{i}^{*}\right)+D_{j}\left(p_{j}^{*}\right)\right]\left(1+\delta \rho+\delta^{2} \rho^{2}+\ldots\right)
$$

Hence, the manufacturer sets a wholesale price

$$
p_{w}^{*}=\frac{\alpha+(1-\beta) c}{2(1-\beta)}
$$

which yields equilibrium profits

$$
\pi_{m}^{*}=\frac{1}{1-\delta \rho} \frac{[\alpha-(1-\beta) c]^{2}}{2(2-\beta)(1-\beta)}
$$




$$
\pi_{i}^{*}=\frac{1}{1-\delta \rho} \frac{[\alpha-(1-\beta) c]^{2}}{4(2-\beta)^{2}} \quad i=A, B
$$

However, this does not necessarily constitute an equilibrium where retailers are able to coordinate a tacit collusion on the monopoly price. By colluding, each retailer earns a stage profit

$$
\pi_{i}^{*}=\left(p_{i}^{m}-p_{w}\right)\left(\alpha-p_{i}^{m}+\beta p_{j}^{m}\right)
$$

where

$p_{i}^{m}=\arg \max _{p_{i}}\left[\left(p_{i}-p_{w}\right) D_{i}\left(p_{i}, p_{j}^{m}\right)+\left(p_{j}^{m}-p_{w}\right) D_{j}\left(p_{i}, p_{j}^{m}\right)\right] \quad i, j=A, B \quad i \neq j$.

Yet, the retailers may not be able to coordinate on the monopoly price. When the deviation from the cartel price at any stage is profitable the collusion may not be stable. Supposing trigger strategies being used by retailers deviation is not profitable if and only if

$$
\frac{1}{1-\delta \rho} \frac{[\alpha-(1-\beta) c]^{2}}{16(1-\beta)}>\frac{(2-\beta)^{2}[\alpha-(1-\beta) c]^{2}}{64(1-\beta)^{2}}+\frac{\delta \rho}{1-\delta \rho} \frac{[\alpha-(1-\beta) c]^{2}}{4(2-\beta)^{2}}
$$

or

$$
\delta \rho>\theta^{c} \equiv \frac{4-4 \beta+\beta^{2}}{8-8 \beta+\beta^{2}}
$$

Therefore, the manufacturer sets $p_{w}$ regarding to (6) if $\delta \rho \leq \theta^{c}$ and obtains the profit equal to (7). On the other hand, when the retailers can collude, the manufacturer's problem boils down to

$$
\max _{p_{w}} \pi_{m}=\frac{1}{1-\delta \rho}\left(p_{w}-c\right)\left[D_{i}\left(p_{i}^{m}, p_{j}^{m}\right)+D_{j}\left(p_{j}^{m}, p_{i}^{m}\right)\right]
$$

where $p_{i}^{m}(i=A, B)$ is given by (10), which yields profit equal to $\frac{1}{1-\delta \rho} \frac{[\alpha-(1-\beta) c]^{2}}{4(1-\beta)^{2}}$. These profits are always smaller than the profit given by (7), if $\beta<1$.

A possible solution to solve the problem caused by double marginalization is to impose a price floor $p_{f}$. This may lead to a less stable cartel by making the 
deviation from the cartel agreement less costly. Under a price floor retailers commit themselves not to charge a price lower than $p_{f}$. We assume that the manufacturer is able to enforce such a contract.

A tacit collusion is feasible if and only if the following condition is satisfied

$$
\begin{aligned}
\frac{1}{1-\delta \rho}\left(p_{i}^{m}-p_{w}\right)\left(\alpha-p_{i}^{m}+\beta p_{j}^{m}\right)> & \left(p_{i}^{d}-p_{w}\right)\left(\alpha-p_{i}^{d}+\beta p_{j}^{m}\right)+ \\
& \frac{\delta \rho}{1-\delta \rho}\left(p_{f}-p_{w}\right)\left(\alpha-p_{f}+\beta p_{f}\right)
\end{aligned}
$$

for every $i=A, B(i \neq j)$, where

$$
p_{i}^{d}=\arg \max _{p_{i}}\left[\left(p_{i}-p_{w}\right)\left(\alpha-p_{i}+\beta p_{j}^{m}\right)+\left(p_{j}^{m}-p_{w}\right)\left(\alpha-p_{j}^{m}+\beta p_{i}\right)\right] .
$$

The right-hand side of the above condition is increasing in $p_{f}$ if $\delta \rho>\theta^{c}$ and $p_{f} \in\left(p_{w}^{*}, p^{m}\right)$, where $p_{w}^{*}$ is given by $(6)$ and $p^{m}=\max \left\{p_{i}^{m}, p_{j}^{m}\right\}$, where $p_{i}^{m}$ is given by (10). It is easy to show that for a profit maximizing manufacturer a price floor equal to $p^{m}$ always dominates any price floor bigger then $p^{m}$, moreover a price floor smaller than $p_{w}^{*}$ can not destabilize a cartel which is feasible next to $p_{w}^{*}$. Thus to destabilize a cartel a reasonable price floor to choose is the smallest $p_{f}$ which still violates condition (13). The manufacturer's problem can be given by

$$
\begin{gathered}
\max _{p_{w}} \pi_{m}=\left(p_{w}-c\right)\left[D_{i}\left(p_{f}, p_{f}\right)+D_{j}\left(p_{f}, p_{f}\right)\right] \\
\text { s.t. } \frac{1}{1-\delta \rho}\left(p_{i}^{m}-p_{w}\right)\left(\alpha-p_{i}^{m}+\beta p_{j}^{m}\right)= \\
\\
\\
\frac{\left(p_{i}^{d}-p_{w}\right)\left(\alpha-p_{i}^{d}+\beta p_{j}^{m}\right)+}{1-\delta \rho}\left(p_{f}-p_{w}\right)\left(\alpha-p_{f}+\beta p_{f}\right)
\end{gathered}
$$

which yields

$$
\begin{gathered}
p_{w}^{*}=\frac{\alpha+(1-\beta) c}{2(1-\beta)} \\
p_{i}^{*}=p_{f}^{*}=\frac{2 \delta \rho[3 \alpha+(1-\beta) c](1-\beta)-\beta[\alpha-(1-\beta) c] \sqrt{\delta \rho(1-\delta \rho)(1-\beta)}}{8 \delta \rho(1-\beta)^{2}}
\end{gathered}
$$




$$
\begin{gathered}
\pi_{m}^{f *}=\frac{1}{1-\delta \rho} \frac{[\alpha-(1-\beta) c]^{2}[2 \delta \rho(1-\beta)+\beta \sqrt{\delta \rho(1-\delta \rho)(1-\beta)}]}{8 \delta \rho(1-\beta)^{2}} \\
\pi_{i}^{f *}=\frac{1}{1-\delta \rho} \frac{[\alpha-(1-\beta) c]^{2}\left[4 \delta \rho(1-\beta)-(1-\delta \rho) \beta^{2}\right]}{64 \delta \rho(1-\beta)^{2}}
\end{gathered}
$$

Hence, if retailers can engage in a tacit collusion a manufacturer will impose a price floor to destabilize the cartel if and only if its profit next to a price floor $\left(\pi_{m}^{f *}\right)$ is higher than its profit without a price maintenance $\left(\pi_{m}^{*}\right)$, that is, when

$$
\frac{1}{1-\delta \rho} \frac{[\alpha-(1-\beta) c]^{2}[2 \delta \rho(1-\beta)+\beta \sqrt{\delta \rho(1-\delta \rho)(1-\beta)}]}{8 \delta \rho(1-\beta)^{2}}>\frac{1}{1-\delta \rho} \frac{[\alpha-(1-\beta) c]^{2}}{4(1-\beta)^{2}}
$$

The above inequality holds if $\beta<1$ which is the case by assumption. Thus, as in the case of symmetric retailers (see Overvest (2010)), a manufacturer is always better off by introducing a price floor for its product when retailers have the incentive to engage in tacit collusion. This result is summarized in the following

Proposition 2.1 If $\delta \rho \leq \theta^{c}$ the retailers compete in Bertrand fashion and set the prices given by (3). The manufacturer sets $p_{w}$ such that $\pi^{m}$ is maximized. If $\delta \rho>\theta^{c}$ the retailers would engage in tacit collusion but the manufacturer prevents this collusive behavior by imposing a price floor. The manufacturer sets a price floor given by (15), which is higher than the wholesale price. Retailers acquire positive profits, the manufacturer gains from inducing a price floor.

What drives this conclusion is the fact that retailers can profit from a collusion if the firms are patient enough, which has a negative effect on the manufacturer's profit. Accordingly, the manufacturer has an incentive to prevent a cartel in the retail market. One way to do this is to impose a price floor.

Having a closer look at the optimal price floor imposed by the manufacturer we can examine how it is affected by the degree of product differentiation. Taking the first derivative of the expression (15) with respect to $\beta$ yields 


$$
\frac{\partial p_{f}^{*}}{\partial \beta}=\frac{3 \alpha}{4(1-\beta)^{2}}-\frac{(1-\delta \rho)[\alpha(2+\beta)-c(1-\beta)(2-\beta)]}{16(1-\beta)^{2} \sqrt{\delta \rho(1-\delta \rho)(1-\beta)}}
$$

which is strictly positive whenever $\delta \rho>\theta^{c}$. This yields the following

Proposition 2.2 The optimal price floor is decreasing in the degree of product differentiation.

So, a $\beta$ close to 1 requires a relatively higher price floor than a $\beta$ close to zero. To understand the reason why a manufacturer introduces a higher price floor in the case of less differentiated products, let us consider the case when retailers sell close substitutes. When selling close substitutes, symmetric retailers earn zero profit without collusion and have a strong incentive to sustain a tacit collusion. Therefore, to prevent the cartel a manufacturer has to impose a price floor which is high enough to make the retailers' deviation from the cartel agreement profitable. On the other hand when products are almost independent, that is when $\beta$ is close to zero, the cartel becomes harder to sustain and as a result a smaller price floor can make the cartel unstable.

\section{Conclusion}

The purpose of this paper is to show that a manufacturer has an incentive to impose a price floor to enhance competition and not collusion as the prevailing literature states. In contrary it demonstrates that the price floor may bear an anti-collusion effect. The notion was introduced by Overvest (2010) in a special model based on a homogenous Bertrand competition. In this article we showed that the main result remains valid even if we suppose differentiated products.

Available empirical results (see Jullien and Rey (2008), Cooper et al. (2005) and Overstreet (1983)) suggest that after a price floor is being imposed by a manufacturer the prices fall in the market which should be plausible after the model 
presented in this article.

\section{References}

Overstreet, Thomas R., Jr. (1983), "Resale Price Maintenance: Economic Theories and Empirical Evidence", Bureau of Economics Staff Report, Federal Trade Commission

Telser, Lester (1960), "Why Should Manufacturers Want Fair Trade?" Journal of Law and Economics, 86-105.

Jullien, Bruno and Rey, Patrick (2008), "Resale price maintenance and collusion" RAND Journal of Economics, 983-1001.

Cooper, James C., Froeb, Luke M., O"Brien, Dan and Vita, G. Michael (2005), "Vertical Antitrust Policy as a Problem of Inference", Federal Trade Commission

Overvest, Bastiaan M. (2010), "A note on collusion and resale price maintenance", European Journal of Law and Economics. Available on the web: http://www.springerlink.com/content/32456627480p76w8/, accessed May 27, 2010 . 